\title{
Fostering Leadership Skills of Young People for Inclusion into the Labour Market
}

\author{
Liudmila Alieva \\ Department of Russian history \\ Pskov State University \\ Lenin Square 2, 180000 Pskov \\ Russian Federation \\ e-mail: Zemkod1922@gmail.com \\ Anna Rybakova \\ Department of Social, general and clinical psychology \\ Russian State Social University \\ Wilhelm Pieck str. 4, 129226 Moscow \\ Russian Federation \\ e-mail: anya_rybakova@list.ru
}

\begin{abstract}
Our paper focuses on studying how building and fostering leadership skills might help young people to place themselves better on the labour market. The development of the social and economic potential of youth is an important issue that presents an impending task for the educational system, both at the graduate and postgraduate levels. Today' students will become the future leaders who would foster the development of the world economies and bring innovation and prosperity. Thence, it is our task to prepare them well for the new challenges that might await in the globalised and digitalised world of tomorrow.

Nowadays, when many young people experience discrimination on the labour markets and are facing with such issues as unemployment and social exclusion, helping them to develop their inner potential becomes an important endeavour that governments and public sector should undertake.

Our results show that the efforts aimed at developing leadership skills in students would bring fruits and results in preparing qualified and well-trained labour force. Moreover, we show that focusing on the future and adapting the result-oriented approach would pay off in a form of better productivity and profitability.
\end{abstract}

\section{Introduction}

Leadership skills constitute an important part of the education process as far as young people are involved. By communicating at an early stage, the fundamentals associated with the values of leadership and key themes for the navigation in institutional culture, we can directly influence the future of higher education (Tan and Lim 2004).

Nowadays, the ultimate goal of eduction is to develop leaders who share the values of respect, community, professional development, and good corporate governance, while at the same time trying to encourage others to lead and succeed (Sharma and Monteiro 2016). Quite true, this is how education has changed recently. From memorising the material and asking the students to remember everything to the easy access to any information, the educational systems of today should adapt to the new challenges. Instead of pouring the information into students' heads, we should teach them how to work with all available information. Early introduction of leadership can increase the faculty's desire to become a mentor and mentee while encouraging others to challenge themselves to leadership positions within and outside the institution. In addition, all those working in higher education should be allowed to develop themselves on issues that promote an environment of dignity and respect.

For teachers, staff and administrators, the development of inclusive leadership, ethical and human thinking is as important as the development of teaching, research and leadership skills, as education is ultimately about developing the students' human potential, regardless what discipline they study or what profession they exercise (Santovec 2011). In this context, the central goal of humanistic education is the development of thewhole human being through the acquisition of knowledge, skills, competences, ethicsand habits of thought. So far, faculties have been promoted to seniority because of their vast expertise, experience, and scientific achievements (number of publications in international journals), and not because of their leadership qualities. Despite the enormous importance of effective leadership in higher education, concrete proposals for specific development programs are scarce. Such a shortage presents a challenge that leadership education is about, and 
academics need to think more about. Faculty members working directly to advance the institutional mission of teaching, learning, and some research institutions form the central human resource of higher education.

While the role of the faculty has changed over time, leadership has remained critical to teaching innovation, advancing knowledge, and changing many campus policies and practices. However, as several recent publications confirm, this leadership is threatened by a number of recent trends. Greene et al. (2008) argue that these new factors continue to hinder the leadership of faculties by increasing the challenges posed by the faculty's socialization processand the tenure system. One of the key strategies for assisting the faculty in pursuing leadership opportunities is to find ways in which leadership can be considered as an institutional service. During our studies, we heard repeated stories from chairs or deans who found ways to involve the leadership in terms of the terms of office and promotion. Ultimately, such creative faculty management solutions help both the institution and the individual faculty member, addressing some of the challenges posed by the tenure system. As faculties are generally not socialized to be effective leaders for institutional change, role models and mentors can play a central role in promoting leadership.

At colleges with a high degree of leadership, senior colleges provide informal mentoring to new colleges by teaching them the political skills, strategies and tactics that are effective at their respective campuses. Mentoring is often organic, but there must already be a major campus faculty leaderfor this to happen. In locations where there are few executives, it can be helpful to hire trainers forleadership training. It redefined its nomination committee, whose job it was to identify candidates for the board of directors and other leadership positions as a development executive committee. This is largely based on the recognition that an institution that wants to be at the forefront of change in science societies must nurture its leaders. This view is being widely used by organizations (Limb 2014) and people involved in research (Bateman and Mann 2016). For example, higher education institutions may require that at least some new junior faculty members spend their first year of activities related to leadership development, education, the establishment of a research laboratory, and the formulation of teaching and research proposals.

\section{Young people and unemployment}

Previous research has shown that collaboration is often the element that distinguishes between successful youth development initiatives and failed initiatives. As long as such obstacles to cooperation can not be meaningfully eliminated through research and practice, youth development initiatives will continue to be difficult to implement and sustain.

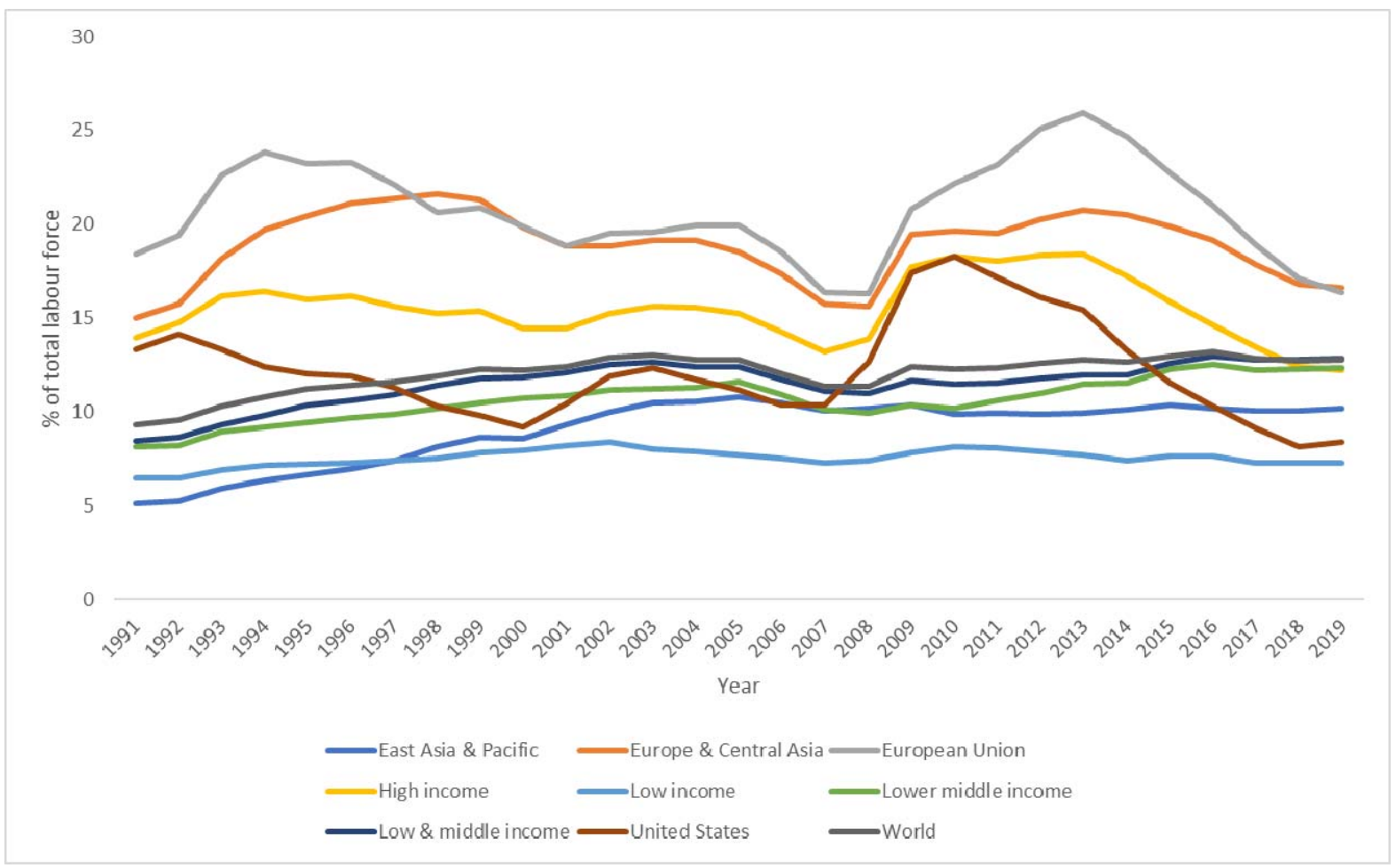

Fig. 1. Unemployment of youth (aged 15-24) in \% to total labour force

Source: World Bank (2019) 
Several studies have found that the basic tenants of the youth development approachare problematic for many participants in youth development initiatives. In addition, staff often have different views on another feature of the youth development approach: the involvement of youth and families in planning and policy development.

Figure 1 above reports the unemployment of young people (i.e. those aged 15-24 according to the classification of International Labour Organisation) in \% to total labour force as a development from 1991 to 2019. One can see the differences between regions and countries. A very alarming issue is the increase in the \% of unemployed among young people in the European Union which spiked around 2013.

Experts and researchers have not yet agreed on a common definition of youth development. They have identified a set of principles common to most programmatic youth development efforts. Youth development efforts focus on satisfying needs and developing skills for all young people, not just those who are involved in problematic behaviors or for whom this is considered vulnerable.

Youth unemployment is a serious problem not because it can have some effects on the economic situation and the labour markets but also because it presents many psychological problems and issues. Unemployed youth can radicalise or experience stress and disorders (Bordea et al. 2017).

In general, youth development model assumes that all adolescents are at risk for problems as they have to go through a specific development process to become successful adults. Youth development programs aim to improve the lives of children and adolescents by satisfying their basic physical, developmental and social needs and helping them build the skills needed to become successful adults (Strielkowski et al. 2016). Examples of youth development programs include community services, mentoring programs and youth centers in the neighborhood. In addition, countless other organizations offer youth development activities with a different focus.

Some countries are affected by the youth-related issues and problems more than others. As a result of the continuing unemployment of millennials in the United States of America, the economy will feel the loss of aggregate demand in the form of slower growth and job creation. To get the U.S. economy going again, people of all ages have to work again. However, the problem of youth unemployment is particularly harmful and, as such, deserves special attention from the legislator. One can clearly see that employment prospects for young Americans are poor both historically and internationally, and we will examine in detail the costs associated with our current youth unemployment in terms of lost earnings, slower economic growth and higher tax burdens. As these changes are also associated with rising unemployment rates, they indicate that young people are leaving the labour market for work-related reasons.

In general terms, the unemployment rate is the share of the unemployed persons in the labor force. Since the WWII, the likelihood of young people becoming unemployed has increased, while the unemployment rate for adults has remained lower and relatively more stable. Nevertheless, demographic growth has slowed in places like North Africa over the past five years, which will reduce tensions in the labor market in the long term. Countries with a high proportion of educated persons are less violent despite high unemployment rates. Another issue in these countries is migration. Nowadays, many young people are eager to leave their homes and to go to live and work abroad to send money back to their home countries. Migration and remittances raise mixed reactions among researchers (see e.g. Rausser et al. 2018).

The opportunity cost for an unemployed young person with low education for a violent rebellion is higher than for an unemployed young person with a higher levelof education. There are also structural factors that affect youth unemployment, such as for example, labour market flexibility determines how easily job demand meets labor supply. Other factors that could be responsible for high youth unemployment include: Rigid labor markets, low economic growth rates, and rapid growth of the young population which increases supply.

\section{Adaptation on the labour market}

One would probably agree with us that employability must be a key component of the education system to avoid imbalances in skills in the labor market. In this sense, close cooperation between companies and relevant government agenciesand institutions is crucial to ensure that the education system curricula meet the needs of the labor market. Optimizing the use of and access to labor market information, as well as harmonizing approaches to the collection and treatment of labor market data across the G20 most developed world's economies, are essential to monitor employment and education trends and to establish consistent education policy plans. In addition, it is very important for human development in all corners of the globe (Cieślik et al. 2016; Orazbayev 2017).

Research shows that younger workers suffer less from discriminatory practices and have more opportunities to find alternative employment and develop new career opportunities simply because they have more time to work before them (Batkovskii et al. 2016). Older workers, on the other hand, are more likely to resign voluntarily than younger workers. In general, job satisfaction is a serious issue that shapes up many processes on the labour market and thus should be taken seriously (Č́ábelková et al. 2015). 
All of the above, poses a risk to older workers as their opportunities to find a new job are limited due to widespread age discrimination in recruitment (Goosey 2019). The situation of younger workers has also deteriorated significantly in recent years. Global economic crisis and financial crisis of the 2008 has led to an unprecedented rise in unemployment rates among the youngest age cohorts (under 25) (Dietrich and Möller 2015). Young people entering the labor market for the first time are always vulnerable to economic downturns as employers reduce their attitudes. In contrast, the position of some older workers has improved, and a small number of employers are actively seeking to hire older workers. Legislation on age discrimination has helped some older people, and the number of employers with formal equality guidelines for old age has increased.

Another indirect evidence emerges from the study of whether labor market outcomes for older workers improve when anti-discrimination laws are enforced or tightened. If there is age discrimination and these laws reduce discrimination, improving labour market outcomes could mean that laws have helped eradicate discrimination. Research indicates that age discrimination laws have improved the labor market outcomes of older workers. For example, Coil and Rice (1995) found that the emergence of state and then state laws on age discrimination strengthened the employment of older workers, and Stock and Beegle (2004) showed that these laws strengthened the employment relationship between older workers and companies, providing them with evidenceThese laws on age discrimination made it difficult for employers to dismiss older workers who had worked for them for a long time. Economists have long studied the impact of discrimination laws on the employment outcomes of sheltered workers. Most of these studies compare older workers before and after a change in the Discrimination Act (e.g. ADEA or change of state laws) with those before and after a change in some unaffected control groups such as younger workers or older workers in states without legal changesor both.

Most studies on age discrimination laws have found positive effects of the laws, while some have found no effects or negative effects. Most studies use the adoption of age discrimination laws before the adoption of ADEA to examine whether the introduction of these laws affects the employment of older workers. In the case the age discrimination seriously hinders the employment of older workers, the political objective of increasing the employment of older adults can be thwarted. The coincidence of age discrimination and measures to promote longer working hours can be particularly problematic. However, if the age discrimination is an omnipresent obstacle to the employment of older workers, policy makers may find that efforts to persuade older Americans to work longer do not lead to a sufficient increase in employment.Indirect evidence of discrimination is based on the observed behavior (ie surveys or other means of collecting data) of older workers compared to other workers or the behavior of other actors towards older and younger workers. For example, older workers may be looking for a smaller subgroup of jobs with lowerphysical demands or maintaining a higher reservation wage (the lowest wage at whichthey would accept a new job) because they have earned higher wages or are less interested in a previous jobworking on some types of jobs.

Another indirect indication of age discrimination is negative stereotypes of older workers. In order to better understand the dynamics of age discrimination in the labor market, we must separate them from age discrimination in other areas of social life (health, law, the media, access to services, etc.). This is due to the fact that age discrimination and age discrimination in the labor market use different chronological ages than guidelines for defining age as in other areas of life. The definition of who is an older worker varies between industries and types of entrepreneurship and between different cultural and local organizational contexts (Dellis et al. 2016).

\section{Students' leadership qualities}

Leadership qualities in students should be pursued both in the families and in the classrooms. It is a long and cumbersome process, but the outcomes are worth it. Leadership should be nourished, and it is an everyday task that requires lot of efforts and time.

Student leaders understand the importance of their relationships with their families and how these relationships affect their leadership style and success. As part of daytime activities, students are asked to do timepressed tasks to develop their decision-making skills. They explore creativity and uniqueness as a management tool, examine their own personal values, plan and work in teams and develop flexibility.

It might be that leadership development helps develop skills that students can translate into adulthood. Educators play a crucial role in influencing the climate, attitudes and prestige oftheir schools. With successful school management, schools become effective incubators of learning places where students are not only trained, but also challenged, encouraged and encouraged. On the other hand, poor or missing school leadership can undermine the goals of an education system. These skills can be developed in schools and classrooms in a variety of ways, including leadership opportunities. Many researchers have found that teaching leadership skills or providing leadership opportunities to students helps them acquire the necessary personal and social skills. Experts say such opportunities should be part of the lesson every day. This benefits the student with the task and the colleagues who need to work with a peer leader. We should try doing this when designing leadership programs, taking into account the entire academic calendar. They need to be able to enable the students to 
develop their skills at a reasonablepace without jumping from beginner to expert in two workshops. Organizing presidents, interns and student mentors will enhance their leadership skills through experience. It is a fact that senior executives among students later become more likely to become executives in a workplace than those who have not previously had leadership experience. Another side of students' leadership experience is that it can be harder to guide others toward graduation. On the one hand, a student leader has more support from faculty members.

The position of a powerful leader in the school or a university requires certain qualities, skills and abilities. Since the complete list of required skills contains many elements, every person in the world usually has at least one quality of a good leader. Although some of them have already been developed, a real leader should never stop learning something new and practicing his achievements to improve the chances of success. An effective leader must also have effective speech and communication skills.

Student leaders need to take time to develop and improve their speaking skills. Good language skills enable leaders to communicate their vision with others, which is an integral part of leadership. If one is unable to share her or his ideas with those she or he leads, it is difficult to be a successful leader. Contrary to popular belief, creativity can not be learned and practiced like many other leadership qualities. Thence, one should make every effort to discover new experiences, learn new things and practice openness by constantly asking new questions. It might be that business creativity comes from the outside (Litau 2018). But one also has to attach great importance to finding time for these creative activities that are not only therapeutic but can also stimulate anyone's professional creativity.

Emphasizing the following behaviors might help to develop leadership qualities in terms of strategic thinking, innovation and action. Young people should be taught how to take a real interest in the world that surrounds them. We should teach them how to focus on the future, understand that changes that are taking place all around us, and maintain a positive outlook. Only by learning these things they might become true leaders one day and contribute to improving the world.

\section{Conclusions}

Generally, it seems appropriate and beneficial to develop students' competencies, innovativeness, and creativity. However, these features should be developed not only in students (or the young people attending the institutions of higher education and pursuing their degrees) but also for the youth in general.

It is clear that young people all around the world experience various problems. Sometimes they can be excluded from the labour market, quite often they are deprived of good education (not only at the university level but also at the secondary level). Thence, it is very important to adapt policies for fostering the young people to adapt to the changing conditions on the market, be able to face the new challenged associated with globalisation and digitalistion, as well as to learn how to adjust to the changes that occur in every day social and economic life effortlessly.

Our results confirm that leadership skills are very important for all of the above. Hence, developing leadership skills in young people and students should become a priority of governments and stakeholders alike.

Young people are our future and they will be the ones shaping up the world in the next decades to come. Therefore, it is a must to provide them with good starting conditions that might include access to education, good jobs, employment security, social and economic protection, as well as overall support and care. Only by investing into the young people today, we can achieve economic prosperity and growth in the future.

\section{References}

Bateman TS, Mann ME (2016) The supply of climate leaders must grow. Nature Climate Change 6(12):10521054. doi: $10.1038 /$ nclimate3166

Batkovskii M, Kalachanov V, Fomina A (2016) Modeling the tasks for training of specialists for military industrial complex. Radio industry (Russia) 3:120-130. doi: 10.21778/2413-9599-2016-3-120-130

Bordea E, Manea M, Pelligrini A (2017) Unemployment and coping with stress, anxiety, and depression. Czech Journal of Social Sciences, Business and Economics 6(2):6-14. doi: 10.24984/cjssbe.2017.6.2.1

Č́belková I, Abrhám J, Strielkowski W (2015) Factors influencing job satisfaction in post-transition economies: the case of the Czech Republic. International Journal of Occupational Safety and Ergonomics 21(4):448-456. doi: 10.1080/10803548.2015.1073007 
Cieślik A, Michałek J, Mycielski J (2016) Globalization, international trade, and human development: a case of Central and Eastern Europe. Czech Journal of Social Sciences, Business and Economics 5(2):6-15. doi: 10.24984/cjssbe.2016.5.2.1

Coil JH, Rice CM (1995) State regulations update: The state of state employment arbitration laws. Employment Relations Today 22(3):95-101. doi: 10.1002/ert.3910220311

Dellis K, Karkalakos S, Kottaridi C (2016) Entrepreneurship Targeting Policies, Technological Growth, and Unemployment. Journal of Eurasian Economic Dialogue 1(6):19-39

Dietrich H, Möller J (2015) Youth unemployment in Europe - business cycle and institutional effects. International Economics and Economic Policy 13(1):5-25. doi: 10.1007/s10368-015-0331-1

Goosey S (2019) Is age discrimination a less serious form of discrimination? Legal Studies 39(3):533-549. doi: 10.1017/1st.2019.7

Greene HC, O’Connor KA, Good AJ, Ledford C, Peel BB, Zhang G (2008) Building a support system toward tenure: challenges and needs of tenure-track faculty in colleges of education. Mentoring \& Tutoring: Partnership in Learning 16(4):429-447. D oi: 10.1080/13611260802433791

Limb M (2014) Leaders must act now to prevent irreversible effects of climate change, say scientists. BMJ 349(nov04 9):g6654-g6654. doi: 10.1136/bmj.g6654

Litau E (2018) Entrepreneurship and economic growth: A look from the perspective of cognitive economics. In: ACM International Conference Proceeding Series, pp. 143-147. doi: 10.1145/3271972.3271978

Orazbayev S (2017) Immigration Barriers and Net Brain Drain. Journal of Eurasian Social Dialogue 2(1):34-59

Rausser G, Strielkowski W, Bilan Y, Tsevukh Y (2018) Migrant remittances and their impact on the economic development of the Baltic States. Geographica Pannonica 22(3):165-175. doi: 10.5937/22-16988

Santovec ML (2011) Take Charge of Building Your Campus Leadership Skills. Women in Higher Education 20(6):1-2. doi: doi.org/10.1002/whe.10200

Sharma R, Monteiro S (2016) Creating Social Change: The Ultimate Goal of Education for Sustainability. International Journal of Social Science and Humanity 6(1):72-76. doi: 10.7763/ijssh.2016.v6.621

Stock WA, Beegle K (2004) Employment Protections for Older Workers: Do Disability Discrimination Laws Matter? Contemporary Economic Policy 22(1):111-126. doi: 10.1093/cep/byh009

Strielkowski W, Tumanyan Y, Kalyugina S (2016) Labour market inclusion of international protection applicants and beneficiaries. Economics \& Sociology 9(2):293-302. doi: 10.14254/2071-789X.2016/9-2/20

Tan A-G, Lim K-M (2004) Singaporean Education Students' Perceptions of Knowledge and Skills as Important for Teachers. Perceptual and Motor Skills 99(2):435-436. doi: 10.2466/pms.99.2.435-436

World Bank (2019) Unemployment, youth total (\% of total labor force ages 15-24) (modeled ILO estimate). https://data.worldbank.org/indicator/SL.UEM.1524.ZS Accessed on 28 November 2019 